\title{
EDUKASI PENGELOLAAN KEUANGAN \\ BAGI PELAKU USAHA MIKRO KECIL DAN MENENGAH DESA GANDU KECAMATAN DAWUAN
}

\author{
Masduki, Moch. Febri Sayidil Umam, Endah Prihartini
}

Universitas Majalengka

masdukimsi67@unma.ac.id

\begin{abstract}
Micro, Small and Medium Enterprises (MSMEs) have an important role in national economic growth and employment. However, business development is often constrained by inadequacy in financial management. Entrepreneurs in Gandu Village have the potential to develop a business, however, there are several problems, including: lack of knowledge about financial institutions, lack of knowledge about banking products, lack of knowledge and skills regarding corporate financial management. Through Community Service which is carried out by providing socialization and education on financial management, Gandu Village MSMEs players no longer borrow funds from loan sharks, are able to make financial plans and are motivated to save and invest, as well as innovate their products and marketing systems
\end{abstract}

Keywords: Banking Product, MSMEs

\begin{abstract}
Abstrak
Usaha Mikro Kecil dan Menengah (UMKM) memilki peran penting dalam pertumbuhan ekonomi nasional dan penyerapan tenaga kerja. Namun demikian, dalam pengembangan usaha sering terkendala oleh kekurangmampuan dalam pengelolaan keuangan. Para pelaku UMKM Desa Gandu berpotensi untuk mengembangkan usaha, namun terdapat beberapa permasalahan antara lain : Masih minimnya pengetahuan tentang lembaga keuangan, masih minimnya pengetahuan tentang produk-produk perbankan, dan masih minimnya pengetahuan dan kemampuan tentang pengelolaan keuanga perusahaan. Melalui Pengabdian Kepada Masyarakat yang dilaksanakan dengan memberikan sosialisasi dan edukasi pengelolaan keuangan, maka pelaku UMKM Desa Gandu tidak lagi meminjam dana kepada rentenir, mampu membuat perencanaan keuangan dan termotivasi untuk menabung dan berinvestasi, serta melakukan inovasi produk dan sistem pemasarannya.
\end{abstract}

Kata Kunci: Produk Perbankan, UMKM

Submitted: 2020-09-03

Revised: $2020-10-05$

Accepted: $2020-10-08$

\section{Pendahuluan}

Perkembangan Usaha Mikro Kecil dan Menengah (UMKM) di Indonesia menurut data dari Kementerian Koperasi dan UMKM, yang dikutif dari Lembaga Pengembangan Perbankan Indonesia (LPPI, 2016), kontribusi UMKM terhadap Produk Domestik Bruto (PDB) nasional pada tahun 2013 adalah 57,6 persen (atas dasar harga konstan), dimana 30,3 persen berasal dari usaha mikro; 12,8 persen dari usaha kecil; dan 14,5 persen berasal dari usaha menengah. UMKM mempunyai tingkat penyerapan tenaga kerja sekitar $97 \%$ dari seluruh tenaga kerja nasional dan mempunyai kontribusi terhadap produk domestik bruto (PDB) sekitar 57\%.

Berdasarkan Peraturan Bank Indonesia (PBI) No. 17/12/PBI/2015 tanggal 25 Juni 2015 tentang Perubahan atas Peraturan bank Indonesia No. 14/22/PBI/2012, dan PBI No. 
14/22/PBI/2012 tentang Pemberian Kredit atau Pembiayaan oleh Bank Umum dan Bantuan Teknis dalam rangka Pengembangan Usaha Mikro, Kecil dan Menengah, Bank Indonesia telah mengeluarkan ketentuan yang mewajibkan kepada perbankan untuk mengalokasikan kredit/pembiayaan kepada UMKM mulai tahun 2015 sebesar 5\%, tahun 2016 sebesar 10\%, tahun 2017 sebesar 15\% dan pada akhir tahun 2018 sebesar 20\% (Bank Indonesia, 2019).

Namun demikian, persoalan klasik seputar pembiayaan dan pengembangan usaha masih tetap melekat pada UMKM. Pemerintah mencatat, pada 2014, dari 56,4 juta UMKM yang ada di seluruh Indonesia, baru $30 \%$ yang mampu mengakses pembiayaan. Dari persentase tersebut, sebanyak 76,1\% mendapatkan kredit dari bank dan 23,9\% mengakses dari non bank termasuk usaha simpan pinjam seperti koperasi. Dengan kata lain, sekitar $60 \%$ - 70\% dari seluruh sektor UMKM belum mempunyai akses pembiayaan melalui perbankan. (Bank Indonesia, 2019).

Persoalan lain muncul menimpa para pelaku UMKM, yaitu sejak awal tahun 2020 perekonomian Indonesia mengalami guncangan dengan adanya Pandemi Covid 19. Hal ini semakin mempersulit para pelaku UMKM baik di perkotaan maupun di pedesaan untuk mampu meningkatkan dan mengembangkan usaha. Banyak pengusaha yang mengalami kerugian bahkan sampai pada titik kebangkrutan.

Walaupun demikian, adanya krisis ekonomi akibat Pandemi Covid 19 ini diharapkan tidak berpengaruh secara signifikan terhadap eksistensi UMKM, dan tetap mampu bertahan bahkan mampu meningkatkan konstribusinya terhadap perekonomian nasional. Harapan ini sangat beralasan, karena telah terbukti ketika terjadi krisis moneter dan krisis ekonomi pada tahun 1998 - 1999, 96 \% UMKM tetap bertahan dari guncangan krisis.

Berikut beberapa peran penting UMKM bagi pertumbuhan ekonomi khususnya di pedesaan :

1) UMKM berperan dalam memberikan pelayanan ekonomi secara luas kepada masyarakat, proses pemerataan dan peningkatan pendapatan masyarakat, dan mendorong pertumbuhan ekonomi,

2) UMKM juga sangat membantu pemerintah dalam hal penciptaan lapangan kerja baru dan lewat UMKM juga banyak tercipta unit-unit kerja baru yang menggunakan tenagatenaga baru yang dapat mendukung pendapatan rumah tangga.

3) UMKM memiliki fleksibilitas yang tinggi jika dibandingkan dengan usaha yang berkapasitas lebih besar, sehingga UMKM perlu perhatian khusus yang didukung oleh informasi akurat, agar terjadi link bisnis yang terarah antara pelaku usaha kecil dan menengah dengan elemen daya saing usaha, yaitu jaringan pasar.

4) UMKM memiliki peran dalam menanggulangi masalah-masalah ekonomi dan sosial seperti tingginya tingkat kemiskinan, ketimpangan distribusi pendapatan, proses pembangunan yang tidak merata antara daerah perkotaan dan perdesaan, serta masalah urbanisasi.

Di samping permasalahan pembiayaan dan pengembangan usaha, permasalahan lain yang dimilki oleh para pelaku UMKM di Kabupaten Majalengka yaitu, sebagaimana hasil penelitian Masduki (2018), salah satu kesimpulannya menyatakan bahwa pelaku UMKM di Kabupaten Majalengka masih kurang memiliki proses pengelolaan pengetahuan, 
sehingga perlu meningkatkan pengelolaan pengetahuan untuk mencapai sasaran strategis perusahaanya.

Selanjutnya, secara khusus membahas para pelaku UMKM di Desa Gandu Kecamatan Dawuan Kabupaten Majalengka, peramasalahan yang saat ini mereka alami berkaitan dengan pembiayaan dan pengembangan usaha antara lain : 1) Masih minimnya pengetahuan tentang lembaga keuangan, sehingga apabila mereka membutuhkan tambahan modal, pinjamnnya kepada lembaga keuangan non bank dengan suku bunga yang sangat tinggi. 2) Masih minimnya pengetahuan tentang produkproduk perbankan, sehingga kurang memiliki keberanian dalam mengakses untuk memperoleh pinjaman. 3) Masih minimnya pengetahuan dan kemampuan tentang pengelolaan keuanga perusahaan.

Berdasarkan permasalahan tersebut, kami mencoba untuk melakukan kegiatan Pengabdian Masyarakat dalam bentuk sosialisasi dan edukasi tentang pengelolaan keuangan bagi pelaku UMKM Desa Gandu Kecamatan Dawuan. Melalui kegiatan ini diharapkan para pelaku UMKM Desa Gandu dapat menambah pengetahuan dan pemahaman tentang pembiayaan serta semakin memiliki kemampuan dalam mengembangkan usaha, sehingga mampu berkonstribusi secara positif yang signifikan bagi pertumbuhan ekonomi di pedesaan.

Kegiatan Pengabdian Kepada Masyarakat ini ini bertujuan untuk :

1) Meningkatkan pemahaman dan pengetahuan tentang lembaga keuangan dan produkproduk perbankan dalam rangka meningkatkan serta mengembangkan usaha.

2) Memberikan pemahaman tentang perencanaan keuangan serta investasi yang aman dan menguntungkan.

3) Memberikan pemahaman tentang peluang dan tantangan usaha di era adaptasi kebiasaan baru pandemi covid 19.

\section{Metode}

Berdasarkan permasalahan yang diuraikan diatas, dan sebagai solusi dari permasalahan tersebut, maka metode pelaksanaan kegiatan pengabdian kepada masyarakat yang akan dilakukan sebagaimana disajikan pada tabel di bawah ini :

Tabel 1. Metode Pelaksanaan dan Sasaran Kegiatan PKM

\begin{tabular}{lll}
\hline \multicolumn{1}{c}{ Solusi } & \multicolumn{1}{c}{ Metode Pelaksanaan } & \multicolumn{1}{c}{ Sasaran } \\
\hline $\begin{array}{l}\text { Sosialisasi tentang Lembaga } \\
\text { Keuangan }\end{array}$ & $\begin{array}{l}\text { 1. Ceramah } \\
\text { 2. Fokus Group Diskusi }\end{array}$ & $\begin{array}{l}\text { Para pelaku UMKM } \\
\text { Desa Gandu } \\
\text { Kecamatan Dawuan }\end{array}$ \\
$\begin{array}{ll}\text { Edukasi tentang Produk-produk } \\
\text { Perbankan }\end{array}$ & $\begin{array}{l}\text { 1. Ceramah } \\
\text { 2. Fokus Group Diskusi }\end{array}$ & $\begin{array}{l}\text { Para pelaku UMKM } \\
\text { Desa Gandu } \\
\text { Kecamatan Dawuan }\end{array}$ \\
\hline
\end{tabular}




\section{Hasil dan Pembahasan}

Sasaran kegiatan pengabdian ini adalah pelaku UMKM Desa Gandu Kecamatan Dawuan, yang terdiri dari beberapa sektor usaha. Contoh pelaku UMKM sektor makanan dan sektor produksi, seperti diperlihatkan pada gambar di bawah ini.
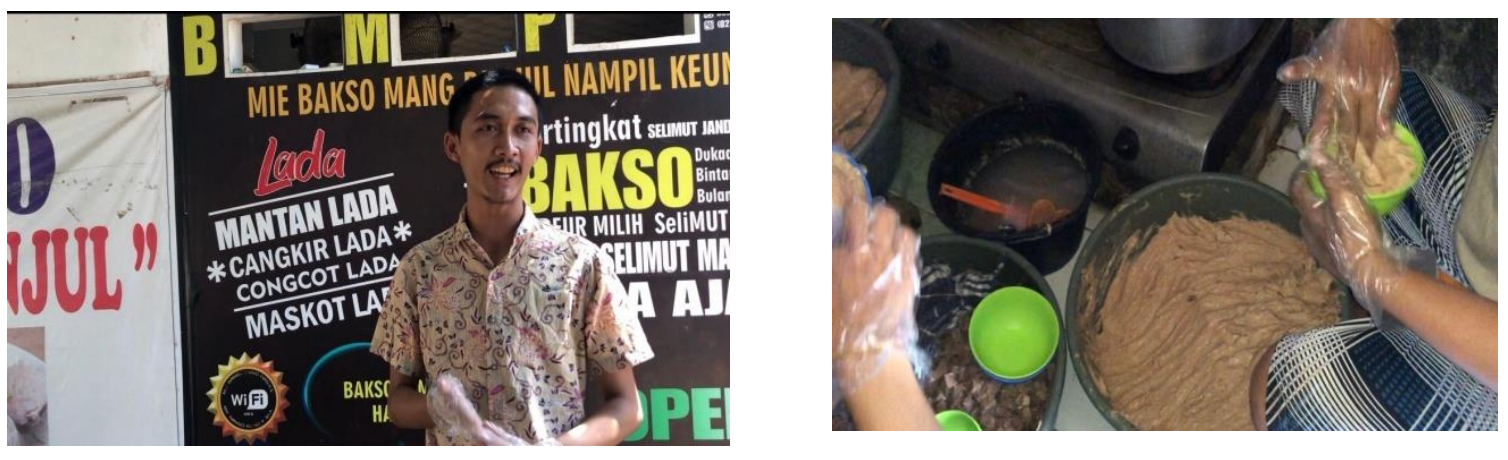

Gambar 1. Proses Produksi Bakso
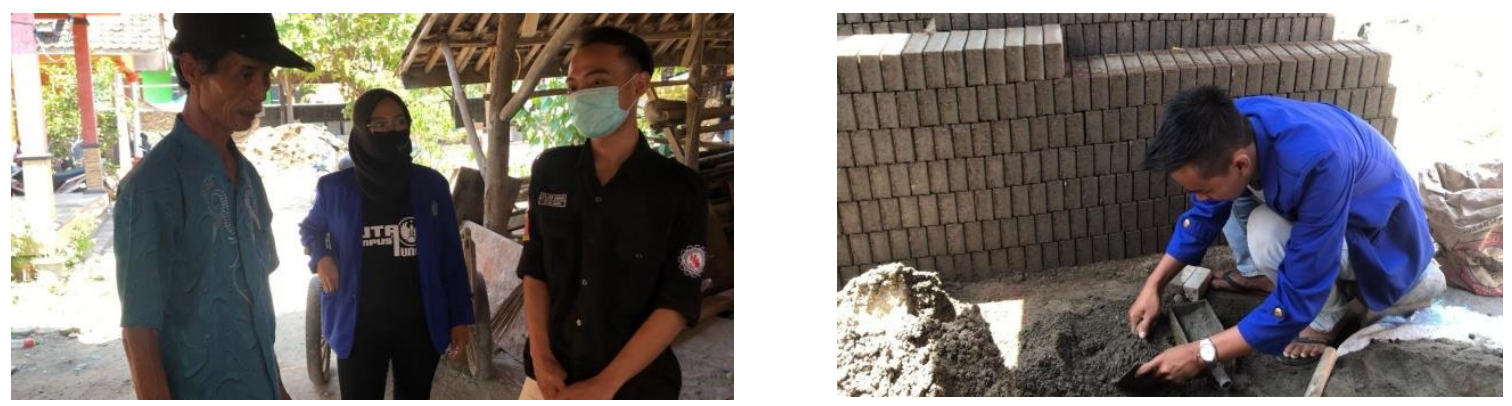

Gambar 2. Proses Produksi Batako

Kegiatan pengabdian kepada masyarakat ini bekerja sama dengan Perusahaan Daerah Bank Perkreditan Rakyat (Perumda BPR) Majalengka. Pelaksanaan kegiatan dapat dilihat pada gambar di bawah ini.
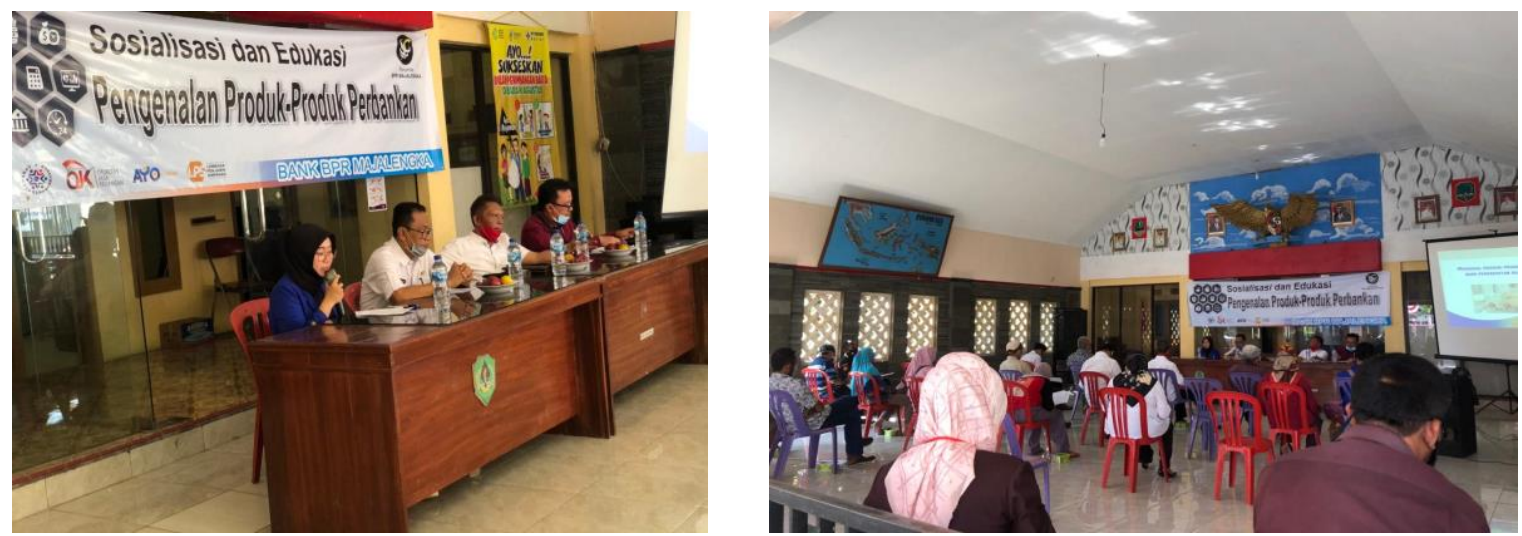

Gambar 3. Pelaksanaan kegiatan pengabdian

Setelah dilaksanakan kegiatan tersebut, maka hasil yang diperoleh adalah sebagaimana dijabarkan sebagai berikut : 
BERNAS:

Jurnal Pengabdian Kepada Masyarakat

Vol.1 No. 4, October 2020, pp. 583-588

Tabel 2. Hasil Pengabdian kepada Masyarakat

\begin{tabular}{|c|c|}
\hline Kegiatan & $\begin{array}{c}\text { Target } \\
\text { (Indikator Kegiatan) }\end{array}$ \\
\hline $\begin{array}{l}\text { Sosialisasi } \\
\text { tentang } \\
\text { Lembaga } \\
\text { Keuangan }\end{array}$ & $\begin{array}{l}\text { 1. } 60 \% \text { pelaku UMKM } \\
\text { di Desa Gandu dapat } \\
\text { mengetahui dan } \\
\text { memahami tentang } \\
\text { Lembaga Keuangan } \\
\text { baik Bank maupun } \\
\text { non Bank. } \\
\text { 2. Pelaku UMKM di Desa } \\
\text { Gandu dapat } \\
\text { mengetahui dan } \\
\text { memahami tentang } \\
\text { risiko melakukan } \\
\text { pinjaman dana usaha } \\
\text { kepada rentenir } \\
\text { dengan suku bunga } \\
\text { yang sangat tinggi. }\end{array}$ \\
\hline
\end{tabular}

Edukasi

tentang

Produk-

produk

Perbankan
Pelaku UMKM di Desa

Gandu (sebagai peserta) dapat mengetahui dan memahami tentang :

1. Produk-produk perbankan.

2. Perencanaan keuangan sederhana melalui menabung.

3. Cara investasi yang aman dan menguntungkan.

4. Peluang dan tantangan usaha di era adaptasi kebiasaan baru pandemi covid 19.

Hasil Kegiatan

(Indikator Capaian)

1. $70 \%$ pelaku UMKM Desa Gandu dapat mengetahui dan memahami tentang lembaga keuangan (Bank dan non Bank) yang legal dan berada dalam pengawasan Otoritas Jasa Keuangan (OJK). Hal tersebut dapat dibuktikan berdasarkan hasil test setelah selesai kegiatan, mereka mampu menyebutkan nama-nama bank seperti Bank BRI, Bank bjb, BCA, Bank Mandiri, dsb., termasuk Perumda BPR Majalengka, serta beberapa nama koperasi.

2. Pelaku UMKM Desa Gandu mengetahui dan memahami tingginya risiko melakukan kredit dengan bunga pengembalian yang sangat tinggi.

Sebagai indikatornya adalah : Pertama, ke depan mereka tidak mau lagi melakukan pinjaman kepada rentenir yang berkedok koperasi, sehingga rentenir yang beroperasi di Desa Gandu dapat diminimalisir. Kedua, apabila mereka membutuhkan tambahan modal usaha, akan mengajukan kredit kepada Bank yang ada di sekitar Desa Gandu, terutama Perumda BPR Majalengka.

1. Pelaku UMKM Desa Gandu dapat mengetahui dan memahami proses bisnis perbankan yaitu produkproduk perbankan, khususnya pada Perumda BPR Majalengka, baik dalam bentuk simpanan maupun kredit. Simpanan berupa tabungan dan deposito, sementara kredit antara lain kredit investasi, kredit modal kerja, dan kredit konsumtif. Dari ketiga jenis kredit tersbut, yang paling terkait dengan pelaku UMKM adalah kredit modal kerja.

2. Pelaku UMKM Desa Gandu dapat mengetahui dan memahami pentingnya pengelolaan keuangan perusahaan yang semestinya terpisah dari urusan keuangan rumah tangga. Selain itu mereka termotivasi juga untuk berupaya menyisihkan sebagian penghasilannya dalam bentuk dana cadangan dengan cara menabung.

3. Pelaku UMKM Desa Gandu mengetahui dan memahami tentang cara berinvestasi yang aman dan menguntungkan. Setelah memahami ini, pengalaman masa lalu diantara meraka yang menginvestasikan dananya di lembaga keuangan abal-abal karena tergiur keuntungan tinggi, tidak terulang lagi.

4. Pelaku UMKM Desa Gandu mengetahui dan memahami tentang kiat-kiat dan strategi usaha dalam menghadapi krisis akibat pandemi covid 19. Untuk meningkatkan jumlah penjualan dan pendapatan, maka dapat dengan cara inovasi produk dan sistem pemasarannya melalui pemanfaatan teknologi informasi yaitu lewat internet (medsos). 


\section{Kesimpulan}

Berdasarkan pelaksanaan dan hasil kegiatan, dapat disimpulkan bahwa : Pertama, pelaku UMKM perlu mengetahui dan memahami lembaga keuangan baik Bank maupun non Bank yang legal dan diawasi oleh pemerintah (OJK), agar tidak terjebak dengan pinjaman dimana suku bunga pengembaliannya sangat tinggi sehingga usahanya sulit untuk maju karena pendapatannya digunakan untuk mengembalikan pinjaman; kedua, pelaku UMKM perlu mengetahui dan memahami produk-produk perbankan, agar memiliki kemampuan dalam membuat perencanaan keuangan dan termotivasi untuk menabung serta berinvestasi pada lembaga keuangan yang tepat; ketiga, pelaku UMKM perlu melakukan inovasi baik produk yang dijual maupun sistem pemasarannya, sehingga akan tetap eksis walaupun di masa era adaptasi kebiasaan baru covid 19.

Berdasarkan kesimpulan diatas, ada beberapa saran yang dapat dikemukakan antara lain sebagai berikut :

1. Bagi pelaku UMKM, agar berhati-hati dalam mengajukan kredit dan berinvestasi, jika membutuhkan penambahan modal kerja lebih baik mengajukan kredit kepada Bank serta apabila menabung dan berinvestasi lebih baik pada lembaga keuangan yang dijamin oleh pemerintah.

2. Bagi Universitas Majalengka, pendampingan pelaku UMKM Desa Gandu harus dapat ditindaklanjuti. Upaya ini dapat dilakuan dengan membentuk Inkubator Bisnis Universitas Majalengka yang dapat memberikan bimbingan dan konseling bagi pengembangan UMKM secara umum.

\section{Daftar Pustaka}

Asep Muhamad Jamaludin, (2020). Mengenal Produk-produk Perbankan, Perumda BPR Majalengka.

Bank Indonesia. (2016). Profil Bisnis Usaha Mikro, Kecil, dan Menengah UMKM). Lembaga Pengembangan Perbankan Indonesia (LPPI), Jakarta

Bank Indonesia. (2019). Profil Bisnis Usaha Mikro, Kecil, dan Menengah UMKM). Lembaga Pengembangan Perbankan Indonesia (LPPI), Jakarta.

Ina Primiana, dkk. (2015). Peningkatan Daya Saing UMKM Jawa Barat dalam Menopang Perekonomian Nasional Menghadapi Persaingan Global. Fakultas Ekonomi Manajemen dan Bisnis, Universitas Padjadjaran, Bandung.

Masduki. (2018). Analisis Keiapan Penerapan Knowledge Management dalam Meningkatkan Daya Saing UMKM di Kabupaten Majalengka. Jurnal Manajemen \& Akuntansi MAKSI, Vol. 5 No. 1.

Universitas Majalengka. (2019). Keputusan Rektor Universitas Majalengka Nomor : 137/KEP/UNMA/IX/2019 Tentang Pengesahan Panduan Hibah Penelitian dan Pengabddian Kepada Masyarakat Universitas Majalengka. 